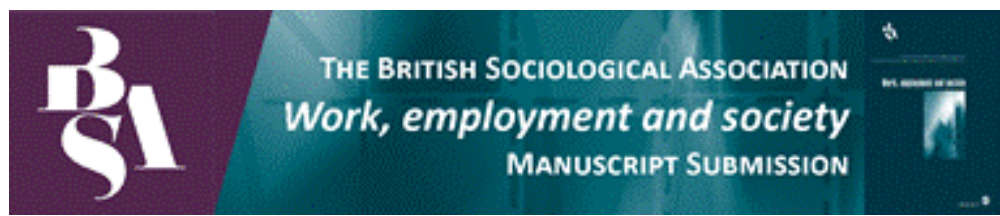

\title{
Management millennialism: designing the new generation of employee
}

\begin{tabular}{|r|l|}
\hline Journal: & Work, Employment and Society \\
\hline Manuscript ID & WES-Jul-2017-ARTC-379.R2 \\
\hline Manuscript Type: & Original Manuscript \\
\hline Keywords: & $\begin{array}{l}\text { Generations, Millennials, Human resource management, Management } \\
\text { fashions, Performance management, Mangement fads and fashions }\end{array}$ \\
\hline \multicolumn{2}{|l}{} \\
\hline
\end{tabular}

\section{SCHOLARONE \\ Manuscripts}




\title{
Management millennialism: designing the new generation of employee
}

\author{
Glynne Williams \\ University of Leicester, UK
}

\begin{abstract}
The idea that society can be divided into discrete generations, each with its own essential characteristics, is treated with caution in sociology, but has had considerable influence among HRM writers and practitioners. 'Millennials' - today's young adults - are said to bring unique attributes to the workplace that may fit uneasily with current management practice. Give the well-documented weakness of generational categories, both in analysis and practice, this article asks how the archetype of the Millennial has taken such a hold. By focusing on recruitment and training within a large company, the article argues that the idea of the Millennial has been validated by repetition and imitation, but that it also serves the more rational purpose of respecifying performance criteria. The Millennial has been constructed as a 'challenge', but specifically as a challenge to poor management.
\end{abstract}

\section{Keywords}

Generations, Human resource management, Millennials, Management fashions, Performance management. 


\begin{abstract}
Corresponding author: Glynne Williams, University of Leicester School of Business, University Road, Leicester, LE1 7RH, UK. Email: gw67@1eicester.ac.uk
\end{abstract}

\title{
Introduction
}

With low birth rates, uncertainty about the future availability of migrant labour and the continuing effect of austerity policies on education, there are good reasons for employers to feel that they are competing for young recruits. This is most obviously a question of labour market, skills and demography, but, at least according to many management writers, it also concerns the inherent characteristics of those now entering the workforce. These young workers are held to be markedly different, whether in their capabilities, expectations, or beliefs, from those who preceded them (DeLoitte, 2017a; Gallup, 2016). Therefore, old ways of managing will not suffice (Ng et al. 2015).

Generational categories have become commonplace in the practitioner press and have also been lent respectability by a growing academic interest in the subject. Notable recent examples include Twenge et al. (2010), Luscombe et al. (2013) and Winter and Jackson (2016). Social scientific accounts are generally sceptical of the more sweeping uses of generations as units of analysis, but this has done little to temper other writing on the subject. At its most enthusiastic, the practitioner and consultancy literature await the impact of generational change with a mixture of enthusiasm and foreboding (PWC, 2011; Gallup, 2016; Hewlett et al., 2009). Even in empirical research, there is a tendency to accept the proposition of generational change as axiomatic: for example, that "members of generations differ in terms of work values, attitudes, and behaviors" (Stone and Deadrick, 2015: 141). The implication for 
management is that, if current recruits are qualitatively different from previous intakes, then perhaps it is employers who need to adapt to the new intake, rather than vice versa. "[T]he time has come to revisit theories that were developed before most of today's employees entered the workforce or were even born" (Anderson et al., 2017).

To the extent that differences between family generations are replicated across society, it may be reasonable to speak of attributes that typify those born during particular eras. A generation, in this sense, may coalesce around core beliefs, influenced by common formative experience (Wohl, 1979). In practice, though, the 'generation' is a troublesome concept: "subjective and a touch poetic" (White, 2013: 216). Most obviously, while generations are easy to distinguish within a single family, no such lines can be drawn in society as a whole. Most commentators sensibly choose to work with generational labels as they find them, accepting the accompanying ambiguity. So, for example, there are wide variations in how the 'Baby Boomer' is defined (Bristow, 2015), and the entire decade of the 1990s is contested between 'Millennials' and 'Generation Z' (CIPD, 2008; Vogel, 2015). This fuzziness reflects the fact that we are not dealing with cohesive groups, defined by their members, but with theoretical categories, usually defined from the 'outside' and with the aim of contrasting supposed differences. It is therefore important to consider not only the validity of generational categories, but also the mechanism by which they come to be employed and the purposes they serve. Given the acknowledged limitations of 'generational thinking', the question addressed here is as follows. Why has the Millennial archetype gained such prominence and what purpose does it serve within employing organisations? 
The following section reviews two contrasting bodies of literature on generational change. The academic debate typically builds on the sociological tradition originating with Manheim (1923/1952), which sees generational identity as the product both of history and of human agency. Management accounts, on the other hand, are often inspired by Strauss and Howe (1997), in whose analysis the Millennial has a largely pre-defined character and a distinctive collective role. Both academic and practitioner literatures tend to take the reality of generational change as their starting point. The article goes on to argue that the strength of the ostensibly weak Millennial archetype lies in its adaptability; it is open to 'reconstruction' as an employer resource (for a comparable discussion of 'work-life balance', see Lewis et al., 2017).

The article examines evidence from a company where the idea of generational change has been taken to heart and where the Millennial serves as a point of reference for human resource management. Drawing on interviews with managers, the article explores the way in which the model was adopted and adapted. On the one hand, 'Millennialism' can be seen as a management fashion whose popularity may have little to do with its validity or usefulness. On the other hand, it may nevertheless serve a practical purpose. In this case the Millennial archetype of popular accounts forms the focus for attempts to redefine performance expectations. The prospect of the coming generation of employees prompts a re-examination of a range of HRM practices, but in a way that is entirely consistent with existing precepts. In effect, the Millennial has been designed according to employer specifications and, in certain formulations, serves as a model for the actual future workforce.

\section{Generations: theory and application}


While social science is generally sceptical about the use of generations as analytic units, the practitioner literature is less cautious. By some accounts the need to understand the new generation is one of the key contemporary challenges for management (for example PWC, 2011). This is because Millennial skills, values and priorities differ markedly from those of their colleagues who were born just a few years earlier. Such is the prominence of this challenge that the very fact that an employer is seen to rise to it has become symbolic of sound management, since "the companies that have already been the most successful in attracting talented millennials... are naturally innovative employers who are never restrained by 'how things used to be done."” (PWC, 2011: 3). In some accounts the challenge is given an additional moral force: “...business has the potential to be a force for positive change that shines through as a core belief of the millennial generation", DeLoitte 2017a: 6). In responding, employers address both internal and external audiences:

Millennials are known to be more purpose-driven, so ... we're always communicating what our values are and trying to be true to those things, (Nathan Blecharczyk, Airbnb, quoted in BBC, 2016)

Individually, many of this generation's supposed defining characteristics are uncontroversial, such as the observation that Millennials tend to be 'tech-savvy' (Vogel, 2015: 50; CIPD, 2015). More ambitiously, though, generations are taken to be empirical categories, each associated with a bundle of essential attributes. In this respect, 'generationalism' (White, 2013) proposes that certain individual attributes can be deduced from birth date alone. Those born between 1980 and 2000, for example, are said to have a distinctive orientation to work, expecting recognition but also interest (Hewlett et al., 2009), structure, but also scope for creativity (Anderson et al., 2017), and for their own values to be reflected in those of their employer (PWC, 
2011; Deloitte, 2017a). This line of writing treats the rather amorphous category of generation as a clear, objective one, whose composite character needs to be understood in order to understand its individual members.

Most sociological writing on the subject builds on, or at least acknowledges Mannheim (1923/1952; Pilcher, 1994). Mannheim began with the self-evident fact that values are formed through experience and therefore that shared experience may prompt the formation of shared identity. The influence of such experience is what makes the difference between an age cohort (a demographic category) and a generation (a social category). Wohl (1979), for example, shows how the 'Generation of 1914' defined itself in conscious distinction to near-contemporaries whose experience of warfare had been very different. Generations, conceived of in this way, are most certainly not universal or predictable.
A historical generation is... not a zone of dates; nor is it an army of contemporaries making its way across a territory of time. It is more like a magnetic field at the center of which lies an experience ... it is relatively independent of age (Wohl, 1979: 210)

Therefore if 'generation' is to mean something more than 'age cohort', it can only make sense as a socially constructed category. A generation may be "an age cohort that comes to have a social significance by virtue of constituting itself as cultural identity" (Edmunds and Turner, 2002: 7, emphasis added). Bristow (2015: 51) for example, shows how the 'Baby Boomer' has been constructed as a social problem but has also "self-consciously constructed their own generation as problematic". This last point is important, since a grouping that initially appears arbitrary may take on 
significance for its members as the narrative becomes the focus of group identity. This, though, is not a claim made of Millennials.

Most academic writing is careful to define terms, but it is still common for 'generation', 'cohort' and 'age group' to be used interchangeably. Although it is possible to be too fastidious about this (see Foster, 2013), it becomes important when temporary age effects are treated as innate and durable (Kertzer, 1983). The idea of generational change implies a) that young people share consistent features, b) that these features contrast with those of the previous generation when young, and c) that generational features are retained as individuals age. These conditions are rarely, if ever, demonstrated. 'Generational' difference has been studied with data from young people alone (George and Wallio, 2017; Luscombe et al. 2013) or is equated with age-related difference (Winter and Jackson, 2016; Dries, 2008). Kuron (2015) provides a useful analysis of age- and cohort-related features, suggesting that Millennials may retain the 'work values' of their youth, but longitudinal studies are notably scarce (see Parry and Urwin, 2017). These limitations aside, the complexity of the problem is generally acknowledged and researchers are wary of using generational change as an independent, still less a causative factor. Those writing from a life-course perspective, for example, draw attention to the way in which contextual factors, including class, gender and geography, shape individual trajectories (e.g Sabelis and Schilling, 2013).

The equivalent formative influence in the management literature is the work of Strauss and Howe $(1991,1997)$, the originators of the term 'Millennial', who see generations as the product of a relatively predictable pattern of history. Successive generations, appearing every twenty years or so, have defined characteristics and these determine the 'spirit of the time'. Generations, in other words, are both effect 
and cause: formed in response to common influences, but with a collective social agency that defines its members. As Bristow (2015) points out, this has more in common with Ortega y Gasset's conception of the generation than with Mannheim's. For Ortega, each new generation appears with a pre-defined purpose or "historical mission" (1931:18), determined by the "rhythm of epochs of old age followed by epochs of youth" (Wohl, 1979: 140). The pulse of generational change is therefore the key to understanding 'metahistory', which Ortega attempts to trace back to the early $17^{\text {th }}$ century. Ortega's theory has received little direct academic support (see Jaeger, 1985), but has commanded considerable influence through the work of Strauss and Howe.

Strauss and Howe claim that the generational cycle has its origins in $15^{\text {th }}$ century England and that the echoes of that time have continued in the New World and the Old (1997: 93). In what is, in some ways, an imaginative tour de force, they go on to characterise subsequent periods of social change in terms of the innate features of each generation. For Ortega, a generation's internal diversity does not alter its “common physiognomy" or its "appointed task" (1931: 19). Similarly, for Howe and Strauss, each generation "possesses its own personal biography [which] every member will have to deal with" (Howe and Strauss, 2000: 41, emphasis added).

Strauss and Howe also describe longer waves in history, whereby generational archetypes repeat themselves over periods of approximately eighty years. For example, 'Generation Z' is said to share features attributed to the pre-war generation. This cycle mirrors that of individual generations: decay and regeneration. As with generational 'personas', the longer cycle has a moral dimension, developed most fully in Howe and Strauss's (2000) profile of the Millennial. The fourth generational 'turning' in each cycle is one that is triggered by social crisis as the maturing 
generation rejects failed institutions and invents new ones. This is the 'Hero' archetype, of which the Millennial is the latest incarnation.

Howe (2017) has disavowed the more apocalyptic connotations of the model, but it nevertheless has a distinctly millenarian flavour. The Millennial represents a “rendezvous with destiny" after the "Unraveling” of their parents' time, which was "a downcast era of strengthening individualism" (1997: 3). The pre-ordained role of the Millennial is to be part of "a good news revolution. This generation is going to rebel by behaving not worse, but better" (Howe and Strauss, 2000: 7).

The extensive management and consultancy literature drawing on this model is often less nuanced than the original. Strauss and Howe, for example, confine most of their generalisations to the USA and acknowledge that their generational divisions are imprecise. Their followers, management consultants prominent among them, often throw such caution to the wind, while the sense of destiny remains:

The millennial generation, now entering into employment, will reshape the world of work. Are you ready? (PWC, 2011: 1)

Millennials are changing the very will of the world. So we, too, must change. (Gallup, 2016: 1)

In a reversal of the orthodox unitarist logic of HR management, employers are told that they need to "understand and align with Millennials' values" (Deloitte, 2016: 17, emphasis added). On the other hand, little alignment appears necessary, since Millennial characteristics include the need for "clear objectives" (CIPD, 2015), a preference for multi-tasking (Foot and Hook, 2011: 14) and openness to mentoring (Deloitte, 2016). Millennials are responsive to extrinsic rewards (Anderson et al. 
2017), but "prioritise support, appreciation and flexibility over salary" (CIPD, 2015:

6). Perhaps most importantly, Millennials are acculturated to job insecurity and expect to build careers by “job hopping” (Vogel, 2015: 49). They are "hungry for the next challenge" (KPMG, 2017: 5). If this list resembles an employer's 'person specification', this may not be entirely accidental since, as the account below will suggest, the Millennial can be thought of as a human resource management project.

\section{The strength of weak ideas}

Since the Millennial archetype appears to rest on weak foundations and "fundamentally flaw[ed]" methods (Parry and Urwin, 2017: 146), it is reasonable to ask why it has been so enthusiastically adopted by practitioners. One sceptical body of enquiry has pointed out that the career of new ideas may have less to do with actual usefulness than with perceived fit with broader trends or with in-built features of management decision making. The argument developed here, on the other hand, is that weak ideas may still serve practical ends. In this case, the Millennial has been pressed into service by management for entirely rational reasons.

One strand of debate sees management language as performative, in the sense that the use of prescribed formulations may be an end in itself. To speak the language of generational transformation is to be transformed. Equally, the rapidly evolving code of management jargon reflects a "desperate search for newness" (Eccles et al., 1992:

2) as managers establish their status as independent innovators (Grint, 1997: 734). By espousing popular ideas, managers also seek to legitimise their own performance (Wilhelm and Bort, 2013). Thus, managers' declared motives may be less influential than other, more symbolic or ceremonial ones (Sturdy, 2004). 
A related interpretation is that, rather than being demonstrably either right or wrong, managers may more often be in the grip of fads or fashions. In uncertain circumstances, that is to say usually, managers are followers, not setters of trends (Abrahamson, 1991) and it may therefore be naïve to evaluate the uptake of an idea in terms of its stated aim alone. This line of enquiry typically aims to characterise the qualities of ideas that give them their impetus within organisations. Giroux (2006), for example, shows how 'pragmatic ambiguity' made the concept of 'quality' adaptable and therefore contributed to its popularity. Consultants and 'gurus' feature large in this literature as intermediaries or evangelists. In the case of the Millennial, the role of the fashion setter is made more complex by the multiple roles held by consultants. Gallup, for example, is a prominent commentator on generational change ("Millennials don't want to fix their weaknesses - they want to develop their strengths": Gallup, 2016:3) and is a leading purveyor of psychometric tests designed to measure these 'strengths'.

For the 'management fads and fashions' literature, ideas themselves tend to be secondary concerns. Since fashions are held to owe their popularity to factors largely independent of the idea itself, they tend to be transient, having a life-cycle determined by other organisational factors. By focusing on the common trajectories of diverse ideas, this literature tends to treat the ideas themselves as artefacts, which, for the purpose of analysis, are interchangeable.

Since the status of the Millennial appears to align with existing management thinking, it should not be dismissed too readily as the product of naivety. It is reasonable to begin with the premise that the effort expended in developing generational models has been for a purpose (see Skinner, 2002). If, for example, Millennials were more likely to value employers' social responsibility policies during economic recession, but to 
prioritise pay and progression during the subsequent recovery (PWC, 2011), then this seems to closely match employer concerns.

One recent case exemplifies the use of generational thinking by employers. In early 2018, a group of 64 UK universities attempted to impose detrimental pension changes on employees, prompting national strike action. An employers' position paper implied that the proposal was, in part, driven by demand and reflected a generational divide among employees:

There is also a growing body of evidence that younger workers are choosing different working patterns ... and this raises the question of whether the current [defined benefit pension] schemes remain appropriate. (UUK, 2017: 29)

The evidence cited for this claim was the PWC report quoted above, which, in turn, was based on an international survey of graduates, including PWC employees (PWC, 2011: 2). It is among such a sample of young people that we might expect to find evidence of global generational change (Beck and Beck-Gernsheim, 2008). Perhaps unsurprisingly, PWC's reported Millennial traits include an expectation of multiple changes of employer. The receptiveness of the management audience may indicate that the conclusions of this variety of research often coincide with existing employer priorities.

The power of ideas has been approached in a more theoretically eclectic manner within industrial relations. Hauptmeier and Heery (2014) bring together explanations from institutional and 'political' approaches to discuss the means by which ideas about work and employment gain legitimacy and traction. They emphasise the "causal properties' of ideas themselves, but argue that these ideas need to be understood in action, which means understanding the agendas of the various actors involved and the 
context in which ideas are deployed. Specifically, an 'ideational turn' (originally in political science) seeks to reassert the role of agency against a tendency to see nonrational institutional constraints as a catch-all explanation. Simms (2016) for example considers the role of ideas in forming and mobilising collective interests. If generational archetypes are regarded in this way, they may be seen as 'narrative resources' that serve to frame pre-existing beliefs and exigencies into a bigger and more compelling story (Levésque and Murray, 2010). The remainder of this article will develop this argument by considering how the Millennial has entered the workplace and been 're-purposed' by human resource management.

\section{The research}

The organisation studied here is a communications company based in Ireland, which will be referred to as Integrated Communications (IC). IC has only a small number of high-profile comparators so, to preserve anonymity, further description will be avoided. Along with these other companies, IC markets itself not only to a Millennial clientele, but also to a potential workforce of Millennials; the link between the two has been an important feature of the consultancy literature (PWC, 2011). Most of its 1,500 current employees are younger than 40 . Size, sector and the influence of global competitors (factors not adequately accounted for in the consultancy literature) mean that IC cannot be regarded as typical; it is selected precisely as an atypical case (Flyvbjerg, 2006). Generational assumptions may often be unacknowledged, but in IC it is the presence of the Millennial in the foreground of everyday working life that makes the company a useful example 
The research itself builds on a series of twenty two interviews with managers about the characteristics of young recruits and their implications for management practice. This discussion extended over twelve months. The initial aim was to explore managers' recruitment priorities and to identify the extent to which the idea of generational change informed practice. The initial sample of eight interviewees comprised senior-middle managers in human resource management, training and recruitment, who were contacted independently via email. During an initial round of interviews in August 2016, it became clear that implicit within IC's approach was a diagnosis of generational change that HR managers found disconcerting. On the other hand, not all managers supported the popular Millennial narrative. Specifically, very senior managers tended to be more sceptical. From this point, the study became focused on the archetype of the Millennial itself and its origins within the company. Follow-up interviews took place during a three day visit to the company in November 2016. This round of interviews relied on 'snowball' type sampling using contacts gained in the first round. The fourteen interviews conducted during this period comprised three tiers of human resource managers, as well as senior managers and directors of ICs main business activities. Individuals were given the choice of meeting in the workplace or elsewhere, and in all cases opted to meet on the premises. These interviews were between 60 and 90 minutes in length and were centred on the interviewee's job role and his/her own engagement with young workers. In four of these cases, further interviews were continued via email and Skype over the following three months. In addition, internal policy documents, training materials, and recruitment selection tools were made available by the company. 


\section{Preparing for the Millennial}

Millennials became official business for IC during 2016. By mid-year, the human resources department had solicited ideas from consultants and academics with the question "How do we need to change in order to attract and retain Millennials?" This reflects concerns expressed by consultancies, for example that $98 \%$ of Irish employers were facing recruitment challenges, while $41 \%$ of employees were dissatisfied with their current prospects (Hays, 2017). The focus of many such reports is graduate 'talent', yet findings are often generalised to the whole workforce. Thus, Deloitte urges Irish employers to prepare for Millennials who "[bring] with them a high expectation for rewarding, purposeful working experience, constant learning, development opportunities and dynamic career progression" (Deloitte, 2017b). On the other hand, despite economic growth since the 2008 crash, youth unemployment in Ireland remained above $15 \%$ throughout 2016 and $25 \%$ of young people were in receipt of benefits at some point during the year (OECD, 2016). As elsewhere, prospects vary according to education and skill level, but for the economy as a whole, labour market 'churn' was lower in 2015 than in 2007 (CSO, 2017). One effect of this is to lock many young people into successive periods of low-paid, precarious work (Times, 2017). So why does the question of recruitment arise now and why in this form? What follows is an attempt to answer this question.

IC claims to be age-blind:

We don't go out saying, "We don't want to hire a 55 year old", just as we don't go out and say, "I hired a man yesterday, so I'll hire a lady today.” But ... you should have that balance. (Director 1) 
Balance, though, is not the most obvious feature of the workforce: "Generation $\mathrm{X}$ doesn't really exist here" (HR Manager 1). This is not literally true, since the HR managers interviewed are all aged between thirty-five and fifty. These managers are clear about the distinction.

There's a huge difference from when I was coming through the ranks. In their behaviour, in their desires, in what they look for ... We understand that, and we need to meet them where they are at, as opposed to corralling them into what we are thinking (HR Manager 2)

Yet this is not a universally shared view. More senior managers express greater scepticism. One director, who describes himself as "several layers away from an individual contributor", comments:

I do sense a shift. There's an expectation for advancement. "If my needs aren't being fulfilled I will move on." ...but my sense is that it's exaggerated somewhat (Director 1)

For 'professional' appointments, length of service is not regarded as an issue: "What's your shelf life in an organisation after all? Two to three years is the norm". However, in HR management accounts, occupational and status differences are elided within generational categories. The challenge of adapting to the Millennial first became apparent during the recruitment process: "All of a sudden, it was as if they were interviewing $u s$ ! And what they wanted was different” (HR Manager 1). The profile that emerges is one of the Millennial as idealistic but also 'entitled', hard-working, yet lacking in application. Managers at the 'sharp end' tend to stress the more negative characteristics. 
How they interact is completely different. Technology is part of their lives and it means that attention spans are short. Even the dialogue we have at home is short bursts of conversations. (Divisional Manager)

The sense of entitlement is still there: "You need me because I'm brilliant", rather than "I'm going to work really hard and this is what I'll do". (Recruitment Manager)

These might equally be regarded as reflections on youth, or perhaps on work intensification, but here they are presented as challenges to the organisation: how to recruit, retain and manage a cohort that is arguably unused to discipline and unmoved by conventional financial incentives. Equally, gendered differences in expectations over the life-course are absent from management accounts; interviewees are, for example, careful to use the gender-neutral 'they' when speaking of Millennials. At the same time, some features of the Millennial, from the employer's perspective, compare favourably with older colleagues. One middle manager, for example, claims that recruits conform fairly closely to the more desirable attributes identified by consultants (PWC, 2011; CIPD, 2015). As will be explained, there are reasons for this focus on 'high performers'.

[My generation] bought into it because we got good pay and career progression. Millennials are not like that...They believe that all going towards one goal is a better thing. They put a lot of importance on the environment they are in. They want to create it... Going back fifteen years people would do the absolute minimum. Now they have a higher value-set. (Recruitment Manager) 
Interviewees speak of young people as idealists, and this accords with the standard description. For example: "[Millennials look] for employers with CSR values that matched their own" (PWC, 2011: 4). On the other hand, these Millennial ideals are poorly formulated, or at least, not expressed in the terms expected by managers.

Before, you would talk about values and religion and education as the things that drive behaviour. Now, when you ask [Millennials] "What are your values?" I get blank stares. I said, "You must have something you hold dear something you live to?" Say Integrity, or Loyalty or Trust, or whatever. You try to explain that, but they have lost it - lost the meaning behind what they do. (HR Manager 4)

The Millennial is a promising yet unfinished resource, much as one would expect a young person to be, but is portrayed as uniquely deficient in certain ways. The job of making good this deficiency falls to the employer. At the same time, the Millennial personifies certain qualities that are prized by employers, including ambitiousness, confidence, the tendency to prioritise intrinsic reward and a facility with technology. However, each of these features has its obverse: impatience, a sense of entitlement, and an inability to think without the aid of gadgets. Both aspects of this composite appear in managers' characterisations.

Their expectation of progression is huge. While they aren't money-oriented, they believe that 18 months in a job should see them promoted ... if they don't get it they'll move on. Tenure is of no significance to them at all. They don't see it as security - it doesn't really touch them - whereas for me it would have been a big thing. (Recruitment Manager) 
Employers need to "recruit, engage and retain the 'right' employees, whose work values align with strategic human resource priorities" (Kuron, 2015:1002). Managers need to modify expectations and bring young workers into line, but they also have to work with the resources they are given. There is a sense that the scope for change is limited: the form of training itself needs to be Millennial-friendly and "have that buzz to it":

They are all about fun. No chalk and talk, no death by powerpoint; they want activities. They've always had their $\mathrm{X}$ boxes and suchlike. So we do gamification. (HR Manager 3)

This 'gamification' is less cutting-edge than might be expected of a technology company: "Bingo, or it could be Monopoly: a bit of fun". However, managers are comparing themselves with their competitors who are doing more sophisticated things.

[Company A] have introduced virtual reality. So they are doing training through headsets. You can programme it ... and you'll be in a classroom with colleagues. That's what they are looking for - things that are different, fun, cool. It's terrifying when you see what they do. (HR Manager 2)

The fashion setter in this case is a larger multinational company based nearby, with a global reputation for 'coolness'. Still this fashion has a purpose: cost-effective training capable of 'engaging' young people. Proximity means that these companies compete for 'talent' and are therefore conscious of differences. A young worker in the head office, for example, aims to get experience in a "more international environment". This will effectively mean moving a few hundred metres. 
In their quest to understand the Millennial, managers turned to these same competitors and the local CIPD group, "to get a feel for what the challenges were". Perhaps unsurprisingly, this discussion confirmed and reinforced the existing view.

We were asking what the younger generation were looking for... And it's all social. It's not about cash. It's your wellbeing. Your social life: "How many nights out are there?" "How can I interact with colleagues?" As opposed to, “How much can I earn?” (HR Manager 2)

This profile is also consistent with the archetype (CIPD, 2015). Many of these ideas are commonplace: for example, Lamm and Meeks (2009: 627) warn against the growing belief "that emulating fun-at-work cultures... will unleash the creative potential". Here, though, these generational adaptations are given urgency by the need to keep up with expectations. So, if presented with old-fashioned training:

They'll think, “This is a bit alien to me, because I'm used to learning by experience, by touch or by feel, and not by written documents or listening to presentations". It's got to be interactive. (Retail Director)

In summary, the Millennial archetype has been adopted at IC as the model for change, but the process of adoption is more diffuse than straightforward emulation. Because they are filtered through the professional network generational ideas are stamped with the status of 'best practice'. Nevertheless, the lessons drawn for management practice appear to be entirely consistent with the extant HR agenda

\section{Re-specifying the Millennial}

The picture of the Millennial presented by managers is more complex than some popular thumb-nail sketches might suggest: a problem, yet in many respects also a 
potential model employee who rejects many of the undesirable characteristics of previous generations. This is consistent with the original characterisation: for example, Howe and Strauss ask, “Are they rule breakers? No. They're rule followers" (2000:8). Above all the Millennial challenges managers to get these rules right. However, the vagueness of the Millennial category means that many variants are possible. At IC it has effectively been customised to fit expected behavioural and performance expectations.

The previous section has shown how stock ideas, some of them questionable, have been reinforced by the competitive dynamics of inter-company discussion. A similar effect is apparent within the company. Whereas HR managers (above) indicate firsthand experience of generational differences, repeated interviews made it clear that the way in which the problem was identified was more complex than first suggested.

So, our Head of Resourcing said, "Look, we are finding this difference - they are interviewing us now, as opposed to us interviewing them." ...The Generation that's coming through is different. (HR Manager 2)

This repeated formulation (see above) suggests a blurring of directly observed features and assumed features. For the Head of Resourcing also, the Millennial profile is a composite based on actual experience and on reports recieved. This interviewee is careful to stress that, "we are looking at this intuitively, rather than looking at data".

Nevertheless, the company does draw on data. Psychometric profiling is used during recruitment and results point in the same direction as the anecdotal evidence. For example, "People [used to be] motivated by stability, but this generation don't mind that it's not a permanent role" (Head of Resourcing). The psychometric test is one of a number of proprietary packages marketed by global consultancies and includes a 
number of routine items such as introversion/extroversion and 'conscientiousness'. Depending on the area of work, the company is also interested in an employee's tolerance for 'role ambiguity' and response to intrinsic and extrinsic motivation. In this case the standard test is adapted to IC's needs, "to suit our environment":

You rank in order of your preferred working style. And you also have what the company's preferred style is - the ideal style. (Head of Resourcing)

This 'ideal', in turn, was developed by examining the profiles of a specially selected sub-set of the existing workforce:

We wanted to work with the high performers, because they are living and breathing our values. We needed to understand what was their preferred working style. (Head of Resourcing)

The 'ideal' personality type, then, is derived from the responses of fifty 'top performers'. Since work routines and work pressures have changed over time, the qualities and behaviours needed to maintain this level of performance have also needed to change:

$80 \%$ of our top performers preferred structured environments, so we need to replicate that in the psychometric. So, you are looking for people who are OK with a very structured routine - every day Johnny checks the stockroom - they are ok working in that type of environment. (Head of Resourcing)

Conversely, and also based on the responses of a 'high performing' subset of employees, the demands of the new generation are seen to call for, and justify, new and arguably more restricted job design: 
[Employees] used to have quite a lot of autonomy. Over the past few years we've been putting more structure in there... The high performers prefer structure to ambiguity.

And this is where it all fits together ... Remember, in college, they've been used to knowing exactly what was happening at every stage. (Head of Resourcing)

In other words, the attributes that are held to typify a generation have been identified through psychometric profiling using scales that were based on the highestperforming group. In order to be selected for this sample, these individuals' behaviour and approach to work has needed to match the pace of reorganisation and technological change. The composite profile is then used as the model for future recruits. It is true that the findings broadly correspond to anecdotal evidence, but even this appears to owe something to the existing profile.

Bridging the gap between actual recruits' profiles and that of the ideal Millennial employee is the job of HR and training managers. Again, this gap widens as work becomes more intensive:

\footnotetext{
Now that jobs are more stressful, you might have one person doing the job of three. So, you need to give that resilience and mindset training to get the emotional intelligence. (HR Manager 2)
}

There is an acceptance that there will be "a higher rate of churn naturally as people with a shorter attention span will think 'it's good to change"” (Divisional Manager). This makes the task of incentivising staff and promoting 'engagement' more difficult. Employee turnover and underperformance are explained by Millennials' tendency to 
walk away from stressful situations. 'Mindset' training is intended to build resilience and application in this introvert generation. One exercise prompts individuals to rate themselves on a scale of 'positivity'.

' 1 ' is "I should never be put in front of a customer - but I recognise it". We then give them exercises to get them back to a ' 10 '. We get units to huddle and ask, "Is everybody at a 10 ?" They manage their state individually and as a team.

Anyone who's unhappy in their job, it makes them think about it. We put them on thirty-day change journey programmes. (Divisional Manager)

In summary, the attempt to engage with the Millennial has resulted in apparent confirmation of some of the reported characteristics. The apparent circularity of management thinking that has led to these conclusions raises questions about the role that the Millennial plays in the organisation. First, the archetype emerges from a process of consultation in which competing brands bid-up the importance of innovation. Second, the internal process of profiling amplifies generational difference by selecting for particular qualities in employees. The Millennial has effectively been re-specified to conform to performance requirements.

\section{Conclusions}

Fineman suggests that, in generational thinking, "the odd grain of truth is developed into an undisputed fact" (2014: 1720). The IC case gives a glimpse of this process in action. The 'grains of truth' are sufficient to distinguish this from pure invention. Certainly, many young recruits hope for variety and progression and may also be less 
reticent about complaining of stagnation and boredom at work. If so, these features might be explicable in terms of education, job design and insecurity. The generational model, though, constructs these highly variable traits as attributes not just of the individual but also of all their contemporaries.

IC is a company that has dedicated time and resources to this question, yet its own assessment of the new generation has been arrived at through an opaque process that has involved the emulation of competitors and an attempt to define real and imagined challenges through a circular process designed to confirm, rather than question, the popular archetype. While the Millennial problem is presented as one of recruitment, retention and training, the most important change has been in job expectations, rather than in new entrants. At its most basic, a perceived mismatch between expected behaviours and the actual behaviour of recent recruits is diagnosed as arising from a change in recruits themselves, rather than any change in what is being expected of them. Since this model does not eradicate diversity within the age group, it may be expected that the impact will be uneven and possibly discriminatory. It is possible that, by 'locking-in' inappropriate, generic criteria, the Millennial profile may make retention less, not more likely.

The weakness of generational archetypes might suggest that they are the product of naivety, or alternatively, cynicism. However, accounts that portray managers as the credulous consumers of fashion may understate the extent to which managers are actively involved in constructing and reconstructing these ideas. Management Millennialism therefore needs to be understood in terms of rational individuals acting in furtherance of actual objectives. Academic treatment of the subject also requires explanation, since it all too often rehearses a sociological critique of the generational approach only to accept its logic. Bristow (2016: 7) notes a "yearning that the 
sociology of generations should provide us with a blueprint for the future". Certainly, the profile of the Millennial outlined above attempts to provide such a blueprint for managers and, to the extent that academic study has adopted the generational model uncritically, it has lent this blueprint legitimacy.

The figure of the Millennial that emerges from this is a complex character: part work problem and part work-hero. Above all, the Millennial is a challenge whose arrival gives a new urgency to management 'best practice' that has long been advocated by the HR 'community'; the Millennial is presented as the Nemesis of bad management. The broad outline of the archetype originates in and is remarkably true to Strauss and Howe's original, but the fully developed character is also the product of subsequent management thinking. A popular narrative, already heavily politically charged, is adapted and 'translated' to meet current priorities and provides the rationale for new expectations of conformity, flexibility and performance. In this sense, the arrival of the Millennial meets with current employer imperatives, just as 'Generation X' met the needs of the ascendant political orthodoxy of the 1980s. For these reasons, management Millennialism makes the case for treating weak ideas seriously.

\section{References}

Abrahamson E (1991) Managerial fads and fashions: the diffusion and rejection of innovations, Academy of Management Review, 16(3): 586-612.

Anderson H, Baur J Griffith J and Buckley R (2017) What works for you may not work for (Gen)Me: Limitations of present leadership theories for the new generation, Leadership Quarterly, 28(1): 245-260. 
Beck U and Beck-Gernsheim E (2008) Global generations and the trap of methodological nationalism for a cosmopolitan turn in the sociology of youth and generation, European Sociological Review, 25(1): 25-36.

Bristow J (2015) Baby Boomers and Generational Conflict, London: Palgrave.

Bristow J (2016) The Sociology of Generations: New Directions and Challenges, London: Palgrave Pivot

BBC (2016) The millennial generation shaking up the workplace rules, $2^{\text {nd }}$ February, http://www.bbc.co.uk/news/business-35460401

CIPD (2008) Gen up: How the four generations work. London: CIPD.

CIPD (2015), Developing the next generation, London: CIPD.

CSO (2014) Job churn - flow of jobs and workers between firms, Central Statistical Office, http://www.cso.ie/en/methods/multisectoral/jobchurn/

Deloitte (2016) The 2016 Deloitte Millennial Survey: Winning over the next generation of leaders, https://www2.deloitte.com

Deloitte (2017a) The Deloitte Millennial Survey: Apprehensive Millennials: Seeking Stability and Opportunities in an Uncertain World, https://www2.deloitte.com

Deloitte (2017b) 2016 Human Capital Trends: Irish Report, www.deloitte.ie

Dries N Pepermans R and De Kerpel E (2008) Exploring four generations' beliefs about career. Is "satisfied" the new "successful”, Journal of Managerial Psychology", 23(8): 907-928. 
Eccles R Nohria N and Berkley J (1992) Beyond the Hype: Rediscovering the Essence of Management, Cambridge MA: Harvard.

Edmunds, J. and Turner, B. (2002), Generations, Culture and Society, Buckingham: Open University Press.

Fineman S (2014) Age matters, Organization Studies, 35(11): 1719-1723.

Flyvbjerg B (2006) Five misunderstandings about case study research, Qualitative Inquiry, 12(2): 219-245.

Foot M and Hook C (2011) Introducing Human Resource Management, Harlow Financial Times - Prentice Hall.

Foster K (2013) Generation and discourse in working life stories, British Journal of Sociology, 64(2): 195-215.

Gallup (2016) How Millennials want to Live and Work, http://www.gallup.com/reports/189830/millennials-work-live.aspx

George J and Wallio S (2017) Organizational justice and millennial turnover in public accounting, Employee Relations, 39 (1): 112-126.

Giroux H (2006) 'It was such a handy term': management fashions and pragmatic ambiguity, Journal of Management Studies, 43:6: 1227-1260.

Grint K (1997) TQM, BPR, JIT, BSCs and TLAs: managerial waves or drownings?, Management Decision, 35(10): 731-738.

Hays (2017) Economic Strength in a Talent-Driven Market, Hayes Ireland, hays.ie. 


\begin{abstract}
Hauptmeier M and Heery E (2014) Introduction: Ideas at work, International Journal of Human Resource Management, 25(18): 2473-2488.
\end{abstract}

Hewlett S Sherbin L and Sumberg K (2009) How Gen Y and Boomers will reshape your agenda, Harvard Business Review, July-August.

Howe N (2017) Where did Steve Bannon get his worldview? From my book, Washington Post, 24 ${ }^{\text {th }}$ February,

Howe N and Strauss W (2000) Millennials Rising: The Next Great Generation, New York: Vintage.

Jaeger H (1985) Generations in history: reflections on a controversial concept, History and Theory, 24(3): 273-292.

Kertzer D (1983) Generation as a sociological problem, Annual Review of Sociology, 9(1): 125-149.

KPMG (2017) Meet the Millennials, https://home.kpmg.com/xx/en/home.html

Kuron L, Lyons S Schweitzer L and Ng E (2015) Millennials’ work values:

differences across the school to work transition, Personnel Review, 44(6): 991-1009.

Lamm E and Meeks M (2009) Workplace fun: the moderating effects of generational differences, Employee Relations, 31(6): 613-631.

Levésque C and Murray G (2010) 'Understanding union power: resources and capabilities for renewing union capacity', Transfer, 16(3): 333-350. 
Lewis S Anderson D Lyonette C Payne N and Wood S (2017) Public sector austerity cuts in Britain and the changing discourse of work-life balance, Work, Employment and Society, 31(4): 586-604.

Luscombe J Lewis I \& Biggs H (2013) Essential elements for recruitment and retention: Generation Y, Education and Training, 55, 272-290.

Mannheim K (1952) The Problem of Generations, in Essays on the Sociology of Knowledge, New York: Routledge \& Kegan Paul: 276-320.

Ng E and Johnson J (2015) Millennials: who are they, how are they different, and why should we care? in Burke R Cooper C and Antoniou A (eds) The Multigenerational and Aging Workforce: Challenges and Opportunities, Cheltenham: Edward Elgar: 121-137.

OECD (2016) Society at a Glance: OECD Social Indicators, http://espas.eu/orbis/sites/default/files/generated/document/en/8116131e.pdf Ortega y Gasset J (1931/1961) The Modern Theme, Harper Torchbooks. Parry E and Urwin P (2017) The evidence base for generational differences: where do we go from here? Work, Aging and Retirement, 39(2): 140-148.

Pilcher J (1994) Mannheim's sociology of generations: an undervalued legacy, British Journal of Sociology, 45(3): 481-495.

PWC (2011) Millennials at Work: Reshaping the Workplace, https://www.pwc.com/gx/en/managing-tomorrows-people/future-ofwork/assets/reshaping-the-workplace.pdf 
Sabelis I and Schilling E (2013) Editorial: Frayed careers: exploring rhythms of working lives, Gender, Work and Organization 20(2): 127-132.

Simms M (2016) Unions and job quality in the UK: extending interest representation within regulation institutions, Work and Occupations, 44(1): 44-67.

Skinner Q (2002) Visions of Politics: Volume One, Regarding Method, Cambridge: Cambridge University Press.

Stone D and Deadrick D (2015) Challenges and opportunities affecting the future of human resource management, Human Resource Management Review, 25(2): 139-145.

Strauss W and Howe N (1991) Generations: The History of America's Future, 1584 to 2069, New York: Harper Perennial.

Strauss W and Howe N (1997) The Fourth Turning: An American Prophecy, New York: Bantam.

Sturdy A (2004) The adoption of management ideas and practices: theoretical perspectives and possibilities, Management Learning, 35(2): 155-179.

Times (2017) Millennials ‘suffering low pay and no job security', 23 October. Twenge J (2010) Generational differences in work, values: leisure and extrinsic values increasing, social and intrinsic values decreasing, Journal of Management, 36(5): 1117-1142.

UUK (2017) Suitability and Sustainability: Pensions in the Higher Education Sector, Universities UK.

Vogel P (2015) Generation Jobless: Turning the Youth Unemployment Crisis into Opportunity, Palgrave. 
White J (2013) Thinking generations, British Journal of Sociology, 64(2): 216-247.

Wilhelm H and Bort S (2013) How managers talk about their consumption of popular management concepts: identity, rules and situations, British Journal of Management, 24(3): 428-444.

Winter R and Jackson B (2015) Work values preferences of Generation Y:

performance relationship insights in the Australian Public Service, International Journal of Human Resource Management, 27(17): 1997-2015.

Wohl R (1979) The Generation of 1914, London: Weidenfeld and Nicolson.

Author biography: Glynne Williams is at the Work and Employment Division, University of Leicester Business School 